\title{
First-Line Use of Core Needle Biopsy for High-Yield Preliminary Diagnosis of Thyroid Nodules
}

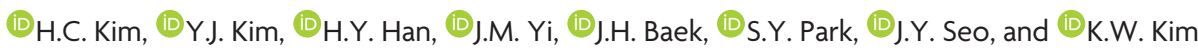

\begin{abstract}
BACKGROUND AND PURPOSE: Although core needle biopsy was introduced as a diagnostic alternative to fine-needle aspiration, the utility and safety of core needle biopsy for thyroid nodules in a large population has yet to be studied comprehensively. We evaluate core needle biopsy yields on a large-scale basis to investigate its potential in the preliminary diagnosis of thyroid nodules.
\end{abstract}

MATERIALS AND METHODS: Between March 2005 and December 2013, 2448 initially detected thyroid nodules from 2120 consecutive patients who underwent core needle biopsy were retrospectively evaluated. Of these, 72 thyroid nodules from 63 patients were excluded due to prior fine-needle aspiration attempts. The inconclusive and conclusive result rates, diagnostic accuracy, sensitivity, specificity, positive predictive value, negative predictive value, and unnecessary surgery rate of core needle biopsy were evaluated.

RESULTS: With core needle biopsy as the first-line method, the inconclusive result rate was $11.9 \%(283 / 2376)$ and the conclusive result rate was $88.1 \%$ (2093/2376). The diagnostic accuracy, sensitivity, specificity, positive predictive value, and negative predictive value of core needle biopsy for the diagnosis of malignancy were $96.7 \%$ (1160/1200), 89.7\% (347/387), 100\% (813/813), 100\% (347/347), and 95.3\% (813/853), respectively. There were no major complications and 12 minor complications.

CONCLUSIONS: We have demonstrated that first-line use of core needle biopsy may well improve diagnostic accuracy in thyroid nodules, reducing inconclusive or false-negative results and unnecessary operations. Such benefits underscore the promising role of core needle biopsy in managing thyroid nodules and optimizing related surgical decision-making.

ABBREVIATIONS: AUS = atypia of undetermined significance; $C N B=$ core needle biopsy; FLUS = follicular lesion of undetermined significance; FNA = fine-needle aspiration; $\mathrm{NPV}=$ negative predictive value; $\mathrm{PPV}=$ positive predictive value; $\mathrm{US}=$ ultrasonography

A lthough ultrasonography (US)-guided fine-needle aspiration (FNA) is a safe, accurate, and cost-effective method for diagnosing malignancy in thyroid nodules, there are limitations. ${ }^{1,2} \mathrm{~A}$ major drawback is the frequency of inconclusive results (ie, inde-

Received February 10, 2016; accepted after revision September 13.

From the Department of Radiology (H.C.K., Y.J.K., J.Y.S., K.W.K.), Konyang University Myunggok Medical Research Institute, Konyang Hospital, Konyang University College of Medicine, Daejeon, Republic of Korea; Department of Radiology (H.Y.H., J.M.Y.), Daejeon Sun Hospital, Daejeon, Republic of Korea; Department of Radiology and Research Institute of Radiology (J.H.B.), University of Ulsan College of Medicine, Asan Medical Center, Seoul, Korea; and Department of Pathology (S.Y.P.), Konyang University Hospital, Konyang University College of Medicine, Daejeon, Republic of Korea

This work was supported by the Konyang University Myunggok Research Fund of 2015.

Paper previously presented at: Annual Meeting of the European Congress of Radiology, March 2-6, 2016; Vienna, Austria.

Please address correspondence to Young Joong Kim, MD, Department of Radiology, Konyang University Myunggok Medical Research Institute, Konyang Hospital, Konyang University College of Medicine, 158 Gwanjeodong-ro, Seo-gu, Daejeon 35365, Republic of Korea; e-mail: myth0318@hanmail.net

三 Indicates article with supplemental on-line tables.

http://dx.doi.org/10.3174/ajnr.A5007 terminate or inadequate results), accounting for $25 \%-30 \%$ of FNA results. ${ }^{2,3}$ In such instances, even repeat FNA attempts may still be nondiagnostic $\left(9.9 \%-47.8 \%\right.$ incidence) ${ }^{4-6}$ Nodules with inconclusive FNA results are commonly referred for diagnostic surgery at reported rates of $22.2 \%-94.7 \% .^{7-9}$ Although several studies suggest that biomarkers (molecular or genetic) and clinical or sonography parameters may serve to support FNA outcomes, ${ }^{10-12}$ surgical confirmation is often still required. ${ }^{1,2,12}$

Core needle biopsy (CNB) was introduced as a diagnostic alternative to FNA or tissue diagnosis. It is well-tolerated and safe and associated with a low incidence of complications. ${ }^{3,4,6,13-16}$ However, its role has remained second-line, largely serving as a supplement in patients with inconclusive FNA results. However, a number of studies have reported that a diagnosis was established via $\mathrm{CNB}$ in up to $98 \%$ of nodules with indeterminate FNA results; and by performing CNB and repeat FNA in combination, $97 \%$ of nodules with prior inadequate FNA yields are eventually diagnosed. ${ }^{4-6,14-16}$ Most interesting, there have been few studies to date on the use of CNB as a first-line examination for the diagnosis of thyroid nodules. ${ }^{17-19}$ Consequently, the utility and safety of 
CNB for thyroid nodules in a large population have not yet been studied comprehensively.

This study was conducted on the premise that highly diagnostic yields are achievable via $\mathrm{CNB}$, without undue or major complications. We therefore evaluated CNB yields on a large-scale basis to investigate its full potential in the preliminary diagnosis of thyroid nodules.

\section{MATERIALS AND METHODS \\ Study Population}

This observational study was approved by the Institutional Review Board of Konyang University Hospital and Daejeon Sun Hospital, with written informed consent for data access waived. However, all patients undergoing $\mathrm{CNB}$ at our facility granted prior informed consent.

Between March 2005 and December 2013, 2448 thyroid nodules detected in 2120 consecutive patients at 2 institutions, Konyang University Hospital $(n=634)$ and Daejeon Sun Hospital $(n=1814)$, were subjected to ultrasound-guided CNB. Of these, 72 thyroid nodules in 63 patients were excluded on the basis of prior FNA attempts. Finally, 2376 initially detected thyroid nodules from 2057 consecutive patients ( 594 men and 1463 women; mean age, $50.8 \pm 12.6$ years, range, $11-91$ years) were enrolled in this study. These enrolled thyroid nodules underwent CNB due to suspicious US findings $(n=1538)$, heavy calcifications $(n=$ $296)$, high vascularity $(n=289)$, and requests of a small group of referring physicians $(n=253)$. The physicians of this cohort preferred the CNB rather than FNA in an attempt to avoid inconclusive FNA results.

Final diagnoses in malignant nodules were confirmed by postsurgical histopathology or other pathologic documentation (including biopsy-proved lymphoma or metastasis). Benign nodules were also confirmed by postsurgical histopathology, by sequential benign $\mathrm{CNB}$ or FNA outcomes (at least twice with intervals of $>6$ months), or by benign CNB findings with a nodule that was stable or decreased in size of after 1 year (at minimum).

\section{Analysis of US Findings}

The US images were reviewed independently by 2 radiologists (Y.J.K., and H.Y.H). The US finding of the nodules were evaluated for following features ${ }^{20,21}$ : the size of thyroid nodules, composition (solid, predominantly solid, predominantly cystic, or cyst), shape (ovoid to round or irregular), orientation (parallel or nonparallel), margin (smooth, spiculated, or illdefined), echogenicity (isoechoic, hypoechoic, markedly hypoechoic, or hyperechoic), and calcifications (none, macrocalcifications, or microcalcifications). The suspicious US findings were defined as nonparallel orientation, spiculated margin, marked hypoechogenicity, and the presence of micro- or macrocalcifications. ${ }^{20,21}$ A suspicious malignant nodule was defined if 1 of the above findings was present. If there were discrepancies in the US findings, the radiologists resolved them by consensus.

\section{Sonography-Guided CNB Procedures}

US examinations were performed by using 1 of 3 US systems: an iU22 or HDI-5000 U (Philips Healthcare, Best, the Netherlands) or a Logiq 9 ultrasound (GE Healthcare, Milwaukee, Wisconsin), each equipped with a high-frequency linear probe $(7-12 \mathrm{MHz})$. All US examinations and US-guided CNBs were performed by 1 of 5 radiologists (Y.J.K., Y.S.P., D.H.O., H.Y.H., or J.M.Y.) with $\geq 5$ years of clinical experience in performing and interpreting US images of the thyroid gland. If the nodule had a cystic portion of $>50 \%$ or necrosis, the internal fluid of the nodule was aspirated at first and then US-guided CNB was performed on the remaining solid portion.

Disposable 1.1-cm excursion 18-ga double-action spring-activated needles (TSK Ace-cut; Create Medic, Yokohama, Japan) were used for $\mathrm{CNB}$, following local anesthetic injection (lidocaine $1 \%$ ). Before insertion, power Doppler US was used to carefully evaluate vessels along the biopsy course to avoid hemorrhage. With a freehand technique, the needle was advanced into a nodule or across its margin to obtain a tissue core, but the thyroid capsule was avoided to prevent vessel injury. Once the nodule was pierced, adjacent vessels were again evaluated to minimize injury and bleeding. We measured the distance of travel $(1.1 \mathrm{~cm})$ before sequential firing of the needle stylet and cutting cannula.

Tissue cores were placed in $10 \%$ buffered formalin immediately at the completion of the procedure for conventional processing. Each patient was then monitored for 10-20 minutes with firm local compression of the biopsy site.

\section{Analysis of CNB Results}

All CNB specimens were reviewed by board-certified attending staff pathologists with $\geq 5$ years of clinical experience (S.Y.P., Y.M.K., B.K.K., and H.J.L.), though thyroid CNB diagnostic criteria were not yet standardized. For this study, the 6 categories of the Bethesda System were used to classify histopathologic CNB results. $^{22}$

In the absence of any identifiable follicular elements or with scant normal follicular content, a CNB was considered nondiagnostic. Benign CNB readings were those demonstrating colloid or hyperplastic nodules and lymphocytic thyroiditis. CNB specimens containing nodules with some atypical cells not diagnostic of malignancy were interpreted as atypia (atypia of undetermined significance [AUS]) or follicular lesions of undetermined significance (FLUSs). These included cellular follicular nodules that were difficult to distinguish (follicular neoplasm versus hypercellular/hyperplastic nodule). Nodules with histologic features favoring follicular neoplasm were categorized as suggestive of follicular neoplasm or consistent with follicular neoplasm. "Suspicious for malignancy" included specimens that displayed atypia of a borderline nature. Unequivocal malignant features were needed for a diagnosis of malignancy.

\section{Statistical Analysis}

The statistical analysis relied on standard software (SPSS Version 18.0 for Windows: IBM, Armonk, New York). Rates of nondiagnostic results, malignancy, inconclusive and conclusive results, unnecessary surgery (considered malignant by $\mathrm{CNB}$ but confirmed as benign or viewed as a follicular neoplasm by CNB but proved to be adenomatous hyperplasia), and complications were determined. Major complications were defined as events that might result in admission to a hospital for therapy, an unplanned 
Table 1: Core-needle biopsy results and final diagnosis for initially detected thyroid nodules ${ }^{\mathrm{a}}$

\begin{tabular}{|c|c|c|c|c|c|c|c|c|c|}
\hline & \multirow[b]{2}{*}{$\begin{array}{l}\text { Total CNB } \\
(n=2376)\end{array}$} & \multicolumn{2}{|c|}{$\begin{array}{l}\text { Final Diagnosis } \\
\qquad(n=1200)\end{array}$} & \multirow[b]{2}{*}{$\begin{array}{c}\mathrm{CNB}<10 \mathrm{~mm} \\
(n=888)\end{array}$} & \multicolumn{2}{|c|}{$\begin{array}{l}\text { Final Diagnosis } \\
\quad(n=455)\end{array}$} & \multirow[b]{2}{*}{$\begin{array}{c}\mathrm{CNB} \geq 10 \mathrm{~mm} \\
(n=1488)\end{array}$} & \multicolumn{2}{|c|}{$\begin{array}{l}\text { Final Diagnosis } \\
\qquad(n=745)\end{array}$} \\
\hline & & $\begin{array}{c}\text { Benign } \\
(n=813)\end{array}$ & $\begin{array}{c}\text { Malignant } \\
(n=387)\end{array}$ & & $\begin{array}{c}\text { Benign } \\
(n=232)\end{array}$ & $\begin{array}{c}\text { Malignant } \\
(n=223)\end{array}$ & & $\begin{array}{c}\text { Benign } \\
(n=581)\end{array}$ & $\begin{array}{c}\text { Malignant } \\
(n=164)\end{array}$ \\
\hline Nondiagnostic & $117(4.9)$ & $19(2.3)$ & $8(2.1)$ & $45(5.1)$ & $4(1.7)$ & $7(3.1)$ & $72(4.8)$ & $15(2.6)$ & $1(0.6)$ \\
\hline Benign & 1549 (65.2) & $734(90.3)$ & $8(2.1)$ & $483(54.4)$ & $218(94.0)$ & $6(2.7)$ & $1066(71.6)$ & $516(88.8)$ & $2(1.2)$ \\
\hline AUS or FLUS & $166(7.0)$ & $44(5.4)$ & $16(4.1)$ & $55(6.2)$ & $6(2.6)$ & $9(4.0)$ & $111(7.5)$ & $38(6.5)$ & $7(4.3)$ \\
\hline FN or SFN & $70(2.9)$ & $16(2.0)$ & $8(2.1)$ & $18(2.0)$ & 4 (1.7) & $1(0.5)$ & $52(3.5)$ & $12(2.1)$ & $7(4.3)$ \\
\hline Suspicious for malignancy & $25(1.1)$ & 0 & $21(5.4)$ & $14(1.6)$ & 0 & $12(5.4)$ & $11(0.7)$ & 0 & $9(5.5)$ \\
\hline Malignancy & 449 (18.9) & 0 & $326(84.2)$ & $273(30.7)$ & 0 & $188(84.3)$ & 176 (11.8) & 0 & $138(84.1)$ \\
\hline
\end{tabular}

Note:-FN indicates follicular neoplasm; SFN, suspicious for a follicular neoplasm.

${ }^{a}$ Data are the number of nodules with percentages in parentheses. Percentages do not add up to $100 \%$ because of rounding.

increase in the level of care, lengthened hospital stay, or events that might lead to substantial morbidity or disability. Other complications such as perithyroid hemorrhage or edema were considered minor complications. $^{23}$

Diagnosis of malignancy included nodules with suspicious for malignancy or malignant $\mathrm{CNB}$ results. Inconclusive results included nondiagnostic and AUS/FLUS readings. With respect to thyroid cancer, CNB was analyzed for diagnostic accuracy, sensitivity, specificity, positive predictive value (PPV), and negative predictive value (NPV).

Subgroup analysis related to sample adequacy was performed according to the nodule size ( $<10 \mathrm{~mm}$ and $\geq 10 \mathrm{~mm}$ ), location (upper/lower and mid), composition (cyst; cystic component $\geq 50 \%$; and solid, cystic component $<50 \%$ ), and the presence and type of calcification. Subgroup analysis related to inconclusive results was also performed according to the nodule size, composition, location, and suspicious US findings. The parameters of the 2 groups were compared by using Student $t$ tests and the $\chi^{2}$ or Fisher exact test. Statistical significance was set at $P<.05$.

\section{RESULTS}

In all patients, CNB procedures were well-tolerated without immediate complications. The mean nodule size was $14.3 \pm$ $9.6 \mathrm{~mm}$ (range, $4-93 \mathrm{~mm}$ ), with nodules $\geq 10 \mathrm{~mm}$ accounting for $62.6 \%$ (1488/2376) of the sample. Among the 888 nodules of $<10 \mathrm{~mm}, 634$ nodules underwent CNB due to suspicious US findings. Two hundred fifty-four nodules with indeterminate US findings underwent CNB to decide the extent of the surgery for multiple thyroid nodules or to evaluate primary malignancy when cervical lymph nodes were diagnosed as metastatic. The mean follow-up was $27.5 \pm 21.9$ months. CNB results $(n=2376)$ and final diagnoses $(n=1200)$ are summarized in Table 1.

\section{Final Diagnosis}

Final histopathologic diagnoses were ultimately acquired in 1200 of 2376 nodules $(50.5 \%)$, all included in the outcome analyses. Of 2376 nodules, 1176 (49.5\%) were neither followed adequately nor surgically removed to confirm prior CNB diagnostic assessments. Malignancies $(n=387)$ were diagnosed following surgical resections $(n=379)$ or biopsy-confirmed specific pathologic results, including metastasis $(n=7)$ or lymphoma $(n=1)$. Benign nodules $(n=813)$ were confirmed by an operation $(193 / 813,23.7 \%)$, sequential benign FNA or
CNB readings (twice at least) $(83 / 813,10.2 \%)$, or a minimum 1 -year follow-up of stable or shrinking nodules considered benign by CNB $(537 / 813,66.1 \%)$.

\section{Diagnostic Utility of First-Line US-Guided CNB}

Study outcomes of CNB as a first-line procedure for a preliminary diagnosis of thyroid nodules are summarized in Fig 1 and Table 2. In terms of detecting malignancy, $\mathrm{CNB}$ displayed a diagnostic accuracy of $96.7 \%$, a sensitivity of $89.7 \%$, a specificity of $100 \%$, a PPV of $100 \%$, and an NPV of $95.3 \%$. The false-negative rate was $1.1 \%(8 / 742)$, with no false-positive results in this study. The diagnostic accuracy and NPV were significantly higher for nodules of $\geq 10 \mathrm{~mm}$ than for nodules of $<10 \mathrm{~mm}$. The malignancy rate was significantly higher for nodules of $<10 \mathrm{~mm}$ (32.3\%) than for nodules of $\geq 10 \mathrm{~mm}$ (12.6\%). Moreover, sensitivity, specificity, and PPV did not show significant differences according to nodule size. Diagnostic accuracy was not associated with the composition and location of thyroid nodules (On-line Table 1).

\section{Sample Adequacy and Conclusiveness}

For CNB readings, the nondiagnostic rate was 4.9\% (117/2376). Of 117 nodules, 38 contained a mix of fibromuscular tissue or normal thyroid tissue, owing to inaccurately targeted biopsies; 59 showed little or no cellular content due to cystic change or necrosis of a nodule; and 20 showed only hemorrhage. Nodule size (10 $\mathrm{mm}$ and $\geq 10 \mathrm{~mm}$ ) and calcification did not affect the sample adequacy. The composition and location of the nodules were associated with the nondiagnostic results (Table 3).

Inconclusive results accounted for $11.9 \%$ (283/2376), whereas $88.1 \%$ (2093/2376) generated conclusive outcomes. According to our subgroup analysis, the orientation, margin, and echogenicity of the nodules were associated with the conclusiveness of CNB results. The composition, size, and calcification of nodules were not associated with the conclusiveness of CNB results (Table 4).

\section{Correlation of CNB Results with Surgical Findings}

Of the 1200 verifiable diagnoses, $813(67.8 \%)$ were benign and $387(32.2 \%)$ were malignant. Five hundred seventy-two nodules $(47.7 \%)$ were surgically resected; these procedures confirmed 379 as malignant and 193 as benign (On-line Table 2).

All 339 nodules considered malignant or suspicious for malignancy by $\mathrm{CNB}$ were confirmed as malignancies at surgery. Of the 24 nodules viewed as follicular neoplasms by CNB, 2 were adeno- 


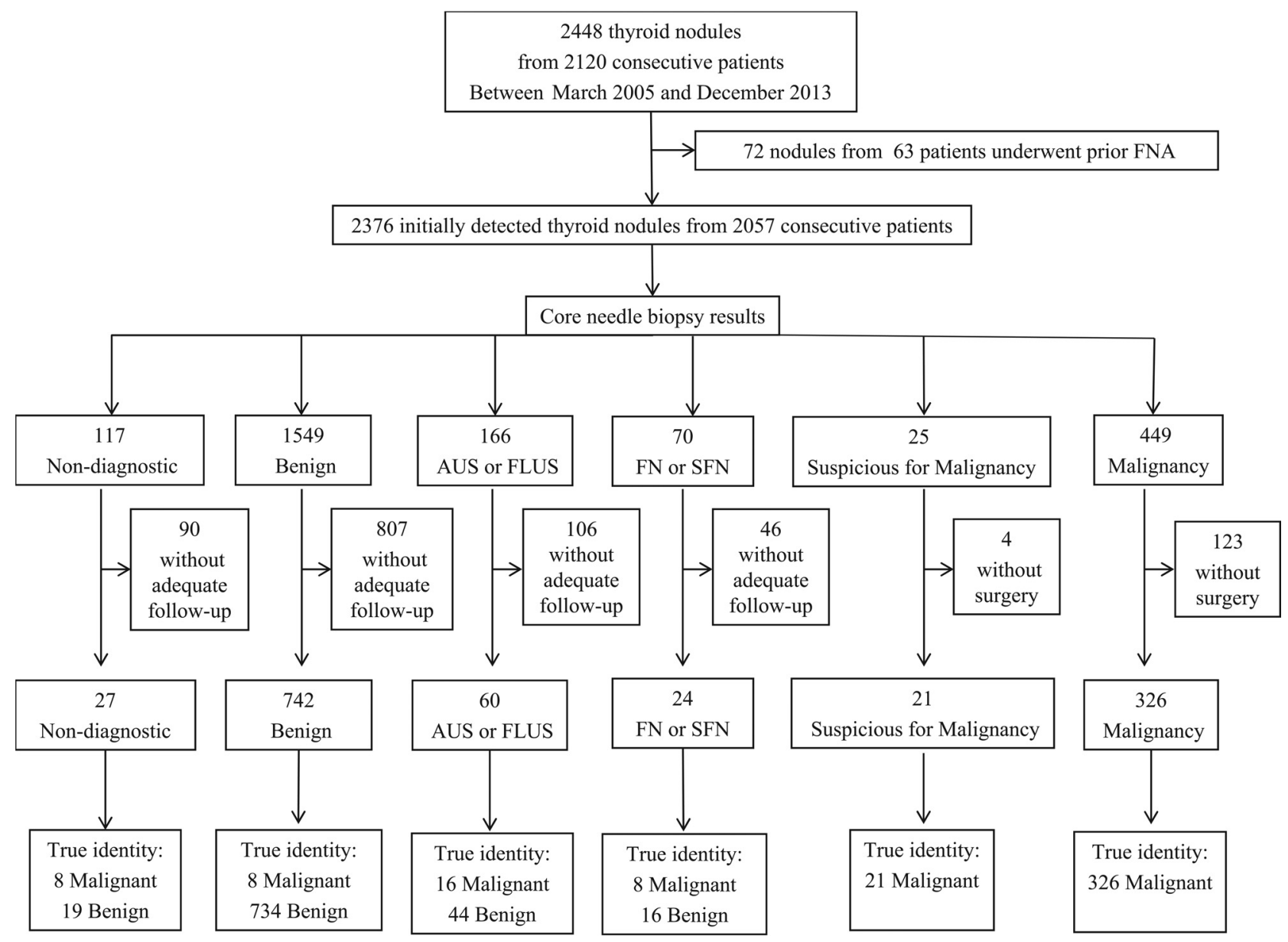

FIG 1. Flow and study outcomes in study patients. Numbers are the number of thyroid nodules. FN indicates follicular neoplasm; SFN, suspicious for a follicular neoplasm.

Table 2: Outcome of CNB for initially detected thyroid nodules

\begin{tabular}{lccccccc}
\hline \multicolumn{1}{c}{ Study Outcomes } & $\begin{array}{c}\text { Incidence } \\
\text { (Total) }\end{array}$ & $\mathbf{9 5 \% \mathrm { Cl }}$ & $\begin{array}{c}\text { Incidence } \\
(<10 \mathrm{~mm})\end{array}$ & $\mathbf{9 5 \% \mathrm { Cl }}$ & $\begin{array}{c}\text { Incidence } \\
(\geq 10 \mathrm{~mm})\end{array}$ & $\begin{array}{c}\boldsymbol{P} \\
\mathbf{9 5 \%} \mathrm{Cl}\end{array}$ & $\mathbf{V a l u e}$ \\
\hline Nondiagnostic & $4.9 \%(117 / 2376)$ & $(4.1-5.8)$ & $5.1 \%(45 / 888)$ & $(3.6-6.6)$ & $4.8 \%(72 / 1488)$ & $(3.8-5.9)$ & .803 \\
Inconclusive & $11.9 \%(283 / 2376)$ & $(10.6-13.2)$ & $11.3 \%(100 / 888)$ & $(9.2-13.4)$ & $12.3 \%(183 / 1488)$ & $(10.6-14.0)$ & .450 \\
Conclusive & $88.1 \%(2093 / 2376)$ & $(86.8-89.4)$ & $88.7 \%(788 / 888)$ & $(86.6-90.8)$ & $87.7 \%(1305 / 1488)$ & $(86.0-89.4)$ & .450 \\
Malignancy & $19.9 \%(474 / 2376)$ & $(18.3-21.6)$ & $32.3 \%(287 / 888)$ & $(29.1-35.6)$ & $12.6 \%(187 / 1488)$ & $(10.9-14.3)$ & $<.001$ \\
Diagnostic accuracy & $96.7 \%(1160 / 1200)$ & $(95.7-97.7)$ & $94.9 \%(432 / 455)$ & $(92.8-96.9)$ & $97.7 \%(728 / 745)$ & $(96.6-98.8)$ & .012 \\
Sensitivity & $89.7 \%(347 / 387)$ & $(86.6-92.7)$ & $89.7 \%(200 / 223)$ & $(85.3-93.4)$ & $89.6 \%(147 / 164)$ & $(84.9-94.1)$ & 1.000 \\
Specificity & $100 \%(813 / 813)$ & $(100.0-100.0)$ & $100 \%(232 / 232)$ & $(100.0-100.0)$ & $100 \%(581 / 581)$ & $(100.0-100.0)$ & 1.000 \\
PPV & $100 \%(347 / 347)$ & $(100.0-100.0)$ & $100 \%(200 / 200)$ & $(100.0-100.0)$ & $100 \%(147 / 147)$ & $(100.0-100.0)$ & 1.000 \\
NPV & $95.3 \%(813 / 853)$ & $(93.9-96.7)$ & $91.0 \%(232 / 255)$ & $(87.3-94.2)$ & $97.2 \%(581 / 598)$ & $(95.8-98.3)$ & $<.001$ \\
Unnecessary surgery & $0.6 \%(2 / 363)$ & $(0-1.4)$ & $0 \%(0 / 163)$ & & $1.0 \%(2 / 200)$ & $(0-2.5)$ & .504 \\
Major complication & 0 & & 0 & & 0 & \\
Minor complication & $0.5 \%(12 / 2376)$ & $(0.3-0.8)$ & $0.6(5 / 888)$ & $(0.1-1.1)$ & $0.5 \%(7 / 1488)$ & $(0.1-0.9)$ & .758 \\
\hline
\end{tabular}

matous hyperplasia. Thus, unnecessary surgery was performed for only 2 nodules $(2 / 363,0.6 \%)$.

Motives for resecting nodules with benign CNB results were image-pathology discordance (benign by CNB but suspicious US features) $(n=21)$, malignancy on follow-up FNA or CNB $(n=$ $5)$, coexistent nodules with a resected nodule $(n=40)$, and patient preference or aesthetic concerns. Of the 21 nodules with image-pathology discordance, 3 proved to be papillary carcinomas. Nodules $(n=48)$ interpreted as AUS/FLUS by CNB were resected to exclude papillary carcinoma. Among them, 12
(63.2\%) were confirmed as malignant (11 papillary carcinomas, 1 follicular variant of papillary carcinoma) in the AUS group ( $n=$ 19 ) and 4 nodules (13.8\%) were confirmed malignant ( 2 papillary carcinomas, 1 follicular carcinoma, and 1 follicular variant of papillary carcinoma) in the FLUS group $(n=29)$.

\section{Complications}

There were no major complications or hospitalizations associated with interventions in our patient cohort. Twelve patients developed minor complications. There was no difference according to 
Table 3: Univariate analysis for factors associated with nondiagnostic result on CNB

\begin{tabular}{lccr}
\multicolumn{1}{c}{ Study Outcomes } & $\begin{array}{c}\text { Nondiagnostic } \\
\text { Results }\end{array}$ & $\begin{array}{c}\text { Diagnostic } \\
\text { Results }\end{array}$ & $\begin{array}{r}\boldsymbol{P} \\
\text { Value }\end{array}$ \\
\hline Nodule size (mm) & $13.3 \pm 8.0$ & $14.4 \pm 9.7$ & .220 \\
$\quad<10 \mathrm{~mm}$ & $45(5.1 \%)$ & $843(94.9 \%)$ & .803 \\
$\geq 10 \mathrm{~mm}$ & $72(4.8 \%)$ & $1416(95.2 \%)$ & \\
Composition (No.) (\%) & & & \\
$\quad$ Solid (cystic component $<50 \%)$ & $98(4.4 \%)$ & $2135(95.6 \%)$ & $<.001$ \\
$\quad$ Cyst (cystic component $\geq 50 \%)$ & $19(13.3 \%)$ & $124(86.7 \%)$ & \\
Calcification (No.) (\%) & & & \\
None & $82(4.9 \%)$ & $1576(95.1 \%)$ & .941 \\
Macrocalcification & $15(4.1 \%)$ & $349(95.9 \%)$ & .441 \\
Microcalcification & $20(5.6 \%)$ & $334(94.4 \%)$ & .494 \\
Location (No.) (\%) & & & \\
Upper/lower & $61(6.4 \%)$ & $896(93.6 \%)$ & .007 \\
Mid & $56(3.9 \%)$ & $1363(96.1 \%)$ & \\
\hline
\end{tabular}

Table 4: Univariate analysis for factors associated with conclusive and inconclusive results on CNB

\begin{tabular}{|c|c|c|c|}
\hline Study Outcomes & Conclusive & Inconclusive & $P$ Value \\
\hline Age (mean) (yr) & $51.2 \pm 12.6$ & $48.5 \pm 12.2$ & $<.001$ \\
\hline $\operatorname{Sex}(M / F)$ & 440:1653 & 44:293 & .032 \\
\hline Nodule size (mm) & $14.2 \pm 9.4$ & $15.4 \pm 10.3$ & .064 \\
\hline$<10 \mathrm{~mm}$ & $788(88.7 \%)$ & 100 (11.3\%) & .450 \\
\hline$\geq 10 \mathrm{~mm}$ & $1305(87.7 \%)$ & $183(12.3 \%)$ & \\
\hline \multicolumn{4}{|l|}{ Composition (No.) (\%) } \\
\hline Solid & $1336(87.4 \%)$ & $192(12.6 \%)$ & .186 \\
\hline Predominantly solid & 95 (84.8\%) & 17 (15.2\%) & .274 \\
\hline Predominantly cystic & $99(84.6 \%)$ & 18 (15.4\%) & .234 \\
\hline Cystic & $4(66.7 \%)$ & $2(33.3 \%)$ & .154 \\
\hline \multicolumn{4}{|l|}{ Shape (No.) (\%) } \\
\hline Ovoid to round & $2033(87.9 \%)$ & $279(12.1 \%)$ & .156 \\
\hline Irregular & $60(93.8 \%)$ & $4(6.3 \%)$ & \\
\hline \multicolumn{4}{|l|}{ Orientation (No.) (\%) } \\
\hline Parallel & 1728 (87.5\%) & 247 (12.5\%) & .047 \\
\hline Nonparallel & $365(91.0 \%)$ & $36(9.0 \%)$ & \\
\hline \multicolumn{4}{|l|}{ Margin (No.) (\%) } \\
\hline Smooth & $1360(85.6 \%)$ & $228(14.4 \%)$ & $<.001$ \\
\hline Spiculated & $366(94.6 \%)$ & $21(5.4 \%)$ & $<.001$ \\
\hline Ill-defined & $367(91.5 \%)$ & $34(8.5 \%)$ & .020 \\
\hline \multicolumn{4}{|l|}{ Echogenicity (No.) (\%) } \\
\hline Isoechoic & $767(88.5 \%)$ & $100(11.5 \%)$ & .667 \\
\hline Hypoechoic & $913(86.0 \%)$ & 149 (14.0\%) & .004 \\
\hline Markedly hypoechoic & $402(92.6 \%)$ & $32(7.4 \%)$ & .001 \\
\hline Hyperechoic & $11(84.6 \%)$ & $2(15.4 \%)$ & .662 \\
\hline \multicolumn{4}{|l|}{ Calcification (No.) (\%) } \\
\hline None & 1456 (87.8\%) & 202 (12.2\%) & .533 \\
\hline Macrocalcification & $321(88.2 \%)$ & 43 (11.8\%) & .950 \\
\hline Microcalcification & $316(89.3 \%)$ & $38(10.7 \%)$ & .459 \\
\hline \multicolumn{4}{|l|}{ Location (No.) (\%) } \\
\hline Upper/lower & 1100 (87.6\%) & $156(12.4 \%)$ & .417 \\
\hline Mid & $993(88.7 \%)$ & 127 (11.3\%) & \\
\hline
\end{tabular}

(On-line Table 3). ${ }^{15,17-19,24,25}$ The unnecessary surgery $(0.6 \%)$ rate was also compatible with that in a previous study $(0.5 \%) .{ }^{19}$ There were low rates of minor complications $(0.5 \%)$ without any major complication in the course of biopsy procedures. These findings indicate that $\mathrm{CNB}$ is a safe and reliable method and that repeated biopsies or unnecessary operations are likely to be avoided through this approach.

For small nodules $(<10 \mathrm{~mm})$, the diagnostic performance and the inconclusive or nondiagnostic rate showed no significant difference compared with nodules of $>10 \mathrm{~mm}$ in this study. These findings are similar to the results reported in previous studies, ${ }^{15,19}$ and they suggest that $\mathrm{CNB}$ is a reliable and effective method for evaluating small and large thyroid nodules.

US-guided FNA is safe, relatively accurate, and cost-effective, but inconclusive or false-negative results of FNA are problematic. The inconclusive results of up to $25 \%-30 \%$ (nondiagnostic, $5 \%-17 \%$; AUS/FLUS readings, 3\%-18\%) and falsenegative results $(17 \%-21 \%)$ of FNA are the major drawback of this tech-

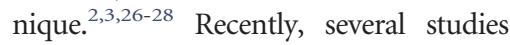
have suggested that $\mathrm{CNB}$ is more useful than repeat FNA for nodules with prior nondiagnostic FNA results, especially if $\mathrm{CNB}$ and FNA are combined. ${ }^{4,5,15,24}$ Some sources have also indicated that $\mathrm{CNB}$ could be more useful for management decisions than repeat FNA in nodules with prior AUS/FLUS. 4,29,30

Several studies have reported factors associated with nondiagnostic FNA results. The following factors were associated with nondiagnostic results of FNA: errors during tissue sampling (experience or skill of the operator, processing errors); interpretation errors; and the nature of the lesions, including cyst

nodule size. All minor complications were successfully managed by manual compression. No needle-tract seeding occurred in association with $\mathrm{CNB}$.

\section{DISCUSSION}

This present study validates the usefulness of CNB as a first-line option for assessing thyroid nodules, accruing a higher rate of conclusive results $(88.1 \%)$ with low inconclusive $(11.9 \%)$ and nondiagnostic $(4.9 \%)$ rates compared with conventional FNA. The diagnostic accuracy of CNB was high (96.7\%), with a PPV of $100 \%$ and no false-positive results. Moreover, the diagnostic performance of this study was consistent with that in previous studies dominancy, small size, type of calcification, vascularity, and benign pathology. ${ }^{31-33}$ Performing repeat FNA for a nodule with a previously nondiagnostic FNA was significantly associated with a repeat nondiagnostic result. ${ }^{34}$ Distinct from FNA, the size of nodules and the presence or type of calcification did not affect the nondiagnostic and inconclusive results of CNB. However, nodules with cystic components, which represented $>50 \%$ of the nodules, showed significantly higher nondiagnostic CNB results. It is important to aspirate the internal fluid of any cystic lesion before the CNB procedure. The location of the nodule was associated with nondiagnostic results in our study. This association 
might be caused by the level of the operator's skill or experience. Most of the CNB procedures were performed via a craniocaudal approach, which could restrict accurate targeting when obstructed by the clavicle or mandible. Although it has been previously reported that the operator's experience does not affect the conclusive results on $\mathrm{CNB},{ }^{19}$ the operator's experience or skill might be a factor.

In our study, there were 8 false-negative cases $(1.1 \%)$ with benign $\mathrm{CNB}$ results consistent with previous studies (0\%$1 \%)^{4,15,24,29}$ This rate remains superior to the false-negative results of FNA, reported up to $17 \%-21 \% .{ }^{35,36}$ A recent study reported that one-third of sonographically suspicious nodules with initially benign cytology were upgraded after CNB, and among them, about $32 \%$ were proved malignant. ${ }^{37}$ False-negative FNA diagnoses may be explained by the nature of the lesions, intrinsic procedural limitations, levels of operator skill/experience, ${ }^{38,39}$ and interpretation errors. ${ }^{40}$ Unlike false-negative findings on FNA, the false-negative results of CNB in our study may reflect inaccurate targeting ( 6 nodules confirmed malignant at follow-up $\mathrm{CNB}$ or FNA, 1 nodule at the posterior margin of lower isthmus, and 1 nodule in a case of lymphocytic thyroiditis) due to procedural inexperience. An advantage of CNB is less operator dependency if the biopsy device successfully penetrates the nodule. ${ }^{15}$ Our study suggested that the ability of accurate targeting of the nodule might be important to reduce false-negative and nondiagnostic results on CNB. Awareness and expertise in several approach methods (transisthmic, craniocaudal, and lateral approaches) might be necessary. ${ }^{41}$

According to the Bethesda system for reporting thyroid cytopathology, the category of AUS/FLUS is related to a FNA specimen that manifests as scenarios of nuclear atypia, architectural atypia, and an oncocytic pattern in paucicellular aspirates. ${ }^{42} \mathrm{Al}-$ though this category is regarded as having inconclusive results, nodules with AUS on FNA showed a significantly higher risk of malignancy than nodules with FLUS on FNA. ${ }^{29}$ Repeat FNA has been recommended for this subcategory, but inconclusive results, including nondiagnostic and AUS/FLUS readings, occur in 20\%$49.1 \%$ of nodules with prior AUS/FLUS FNA results. ${ }^{4,6,27}$ Recently, several studies have shown that CNB is more useful than repeat FNA in cases with previous AUS/FLUS results. ${ }^{4,29,30} \mathrm{Al}-$ though it is possible to get larger tissue samples through CNB procedures, there was still a low rate of AUS/FLUS on CNB for thyroid nodules in this study. It might be caused by the variable heterogeneity of this group and the lack of standardized diagnostic CNB categorization. In our study, malignancy was diagnosed significantly higher in nodules with AUS on CNB (63.2\%) than nodules with FLUS (13.8\%). Further investigations are needed to manage AUS/FLUS on CNB.

Although CNB conducted by experienced radiologists is safe and well-tolerated, there are still safety concerns. ${ }^{6,13,14,43}$ However, we encountered no major complications. To minimize the potential for complications and patient discomfort, technical provisions are in place, including strict color Doppler US monitoring and immediate compression of biopsy sites after CNB procedures. Compared with FNA, CNB may be technically unfeasible or difficult at times (typically in small nodules at the posterior thyroid margin). ${ }^{15}$ Furthermore, CNB can be uncomfortable for the patient, requiring local anesthesia and greater experience in image-guided thyroid interventions.

Our study has several limitations. First, it was a retrospective study performed during a relatively long period. This feature may cause selection bias. This study involved multiple radiologists and pathologists performing US-guided CNB and histopathologic interpretation. Second, up to $50 \%$ of total enrolled cases do not have final results. This lack of results might be due to loss of follow-up or lack of final surgery in 1 (general hospital) of 2 participating hospitals. Finally, we did not apply the standardized diagnostic CNB categorization of a recent publication. ${ }^{22}$

\section{CONCLUSIONS}

We have demonstrated that the first-line use of $\mathrm{CNB}$ may improve the diagnostic accuracy in thyroid nodules, reducing nondiagnostic or inconclusive results. The high PPV and NPV of CNB for a diagnosis of malignancy could prevent repeat biopsy or unnecessary surgery. Such benefits underscore the promising role of $\mathrm{CNB}$ in managing thyroid nodules and optimizing related surgical decision-making.

\section{REFERENCES}

1. Gharib H, Papini E, Paschke R, et al. American Association of Clinical Endocrinologists, Associazione Medici Endocrinologi, and European Thyroid Association medical guidelines for clinical practice for the diagnosis and management of thyroid nodules. J Endocrinol Invest 2010;33(5 suppl):51-56 CrossRef Medline

2. Cooper DS, Doherty GM, Haugen BR, et al; American Thyroid Association (ATA) Guidelines Taskforce on Thyroid Nodules and Differentiated Thyroid Cancer. Revised American Thyroid Association management guidelines for patients with thyroid nodules and differentiated thyroid cancer. Thyroid 2009;19:1167-214 CrossRef Medline

3. Baloch ZW, Cibas ES, Clark DP, et al. The National Cancer Institute thyroid fine needle aspiration state of the science conference: a summation. Cytojournal 2008;5:6 CrossRef Medline

4. Na DG, Kim JH, Sung JY, et al. Core-needle biopsy is more useful than repeat fine-needle aspiration in thyroid nodules read as nondiagnostic or atypia of undetermined significance by the Bethesda system for reporting thyroid cytopathology. Thyroid 2012;22: 468-75 CrossRef Medline

5. Samir AE, Vij A, Seale MK, et al. Ultrasound-guided percutaneous thyroid nodule core biopsy: clinical utility in patients with prior nondiagnostic fine-needle aspirate. Thyroid 2012;22:461-67 CrossRef Medline

6. Park KT, Ahn SH, Mo JH, et al. Role of core needle biopsy and ultrasonographic finding in management of indeterminate thyroid nodules. Head Neck 2011;33:160-65 CrossRef Medline

7. Hryhorczuk AL, Stephens T, Bude RO, et al. Prevalence of malignancy in thyroid nodules with an initial nondiagnostic result after ultrasound-guided fine needle aspiration. Ultrasound Med Biol 2012;38:561-67 CrossRef Medline

8. Lubitz CC, Nagarkatti SS, Faquin WC, et al. Diagnostic yield of nondiagnostic thyroid nodules is not altered by timing of repeat biopsy. Thyroid 2012;22:590-94 CrossRef Medline

9. Jo VY, Vanderlaan PA, Marqusee E, et al. Repeatedly nondiagnostic thyroid fine-needle aspirations do not modify malignancy risk. Acta Cytol 2011;55:539-43 CrossRef Medline

10. Bartolazzi A, Orlandi F, Saggiorato E, et al. Galectin-3-expression analysis in the surgical selection of follicular thyroid nodules with indeterminate fine-needle aspiration cytology: a prospective multicentre study. Lancet Oncol 2008;9:543-49 CrossRef Medline

11. Mathur A, Weng J, Moses W, et al. A prospective study evaluating 
the accuracy of using combined clinical factors and candidate diagnostic markers to refine the accuracy of thyroid fine-needle aspiration biopsy. Surgery 2010;148:1170-77 CrossRef Medline

12. Cibas ES, Ali SZ; NCI Thyroid FNA. The Bethesda system for reporting thyroid cytopathology. Am J Clin Pathol 2009;132:658-65 CrossRef Medline

13. Renshaw AA, Pinnar N. Comparison of thyroid fine-needle aspiration and core needle biopsy. Am J Clin Pathol 2007;128:370-74 CrossRef Medline

14. Screaton NJ, Berman LH, Grant JW. US-guided core-needle biopsy of the thyroid gland. Radiology 2003;226:827-32 CrossRef Medline

15. Sung JY, Na DG, Kim KS, et al. Diagnostic accuracy of fine-needle aspiration versus core-needle biopsy for the diagnosis of thyroid malignancy in a clinical cohort. Eur Radiol 2012;22:1564-72 CrossRef Medline

16. Nasrollah N, Trimboli P, Guidobaldi L, et al. Thin core biopsy should help to discriminate thyroid nodules cytologically classified as indeterminate: a new sampling technique. Endocrine 2013;43: 659-65 CrossRef Medline

17. Trimboli P, Nasrollah N, Guidobaldi L, et al. The use of core needle biopsy as first-line in diagnosis of thyroid nodules reduces false negative and inconclusive data reported by fine-needle aspiration. World J Surg Oncol 2014;12:61 CrossRef Medline

18. Paja M, del Cura JL, Zabala R, et al. Ultrasound-guided core-needle biopsy in thyroid nodules: a study of 676 consecutive cases with surgical correlation. Eur Radiol 2016;26:1-8 CrossRef Medline

19. Suh CH, Baek JH, Lee JH, et al. The role of core-needle biopsy as a first-line diagnostic tool for initially detected thyroid nodules. Thyroid 2016;26:395-403 CrossRef Medline

20. Kwak JY, Jung I, Baek JH, et al; Korean Society of Thyroid Radiology (KSThR), Korean Society of Radiology. Image reporting and characterization system for ultrasound features of thyroid nodules: multicentric Korean retrospective study. Korean J Radiol 2013;14: 110-17 CrossRef Medline

21. Moon W, Baek JH, Jung SL, et al; Korean Society of Thyroid Radiology (KSThR), Korean Society of Radiology. Ultrasonography and the ultrasound-based management of thyroid nodules: consensus statement and recommendations. Korean J Radiol 2011;12:1-14 CrossRef Medline

22. Jung CK, Min HS, Park HJ, et al; Korean Endocrine Pathology Thyroid Core Needle Biopsy Study Group. Pathology reporting of thyroid core needle biopsy: a proposal of the Korean Endocrine Pathology Thyroid Core Needle Biopsy Study Group. J Pathol Transl Med 2015;49:288-99 CrossRef Medline

23. Burke DR, Lewis CA, Cardella JF, et al; Society of Interventional Radiology Standards of Practice Committee. Quality improvement guidelines for percutaneous transhepatic cholangiography and biliary drainage. J Vasc Interv Radiol 2003;14:S243-46 Medline

24. Yeon JS, Baek JH, Lim HK, et al. Thyroid nodules with initially nondiagnostic cytologic results: the role of core-needle biopsy. Radiology 2013;268:274-80 CrossRef Medline

25. Ha EJ, Baek JH, Lee JH, et al. Core needle biopsy can minimise the non-diagnostic results and need for diagnostic surgery in patients with calcified thyroid nodules. Eur Radiol 2014;24:1403-09 CrossRef Medline

26. Nayar R, Ivanovic M. The indeterminate thyroid fine-needle aspiration: experience from an academic center using terminology similar to that proposed in the 2007 National Cancer Institute Thyroid Fine Needle Aspiration State of the Science Conference. Cancer 2009;117:195-202 CrossRef Medline
27. Yassa L, Cibas ES, Benson CB, et al. Long-term assessment of a multidisciplinary approach to thyroid nodule diagnostic evaluation. Cancer Cytopathol 2007;111:508-16 CrossRef

28. Yang J, Schnadig V, Logrono R, et al. Fine-needle aspiration of thyroid nodules: a study of $\mathbf{4 7 0 3}$ patients with histologic and clinical correlations. Cancer Cytopathol 2007;111:306-15 CrossRef

29. Choi YJ, Baek JH, Ha EJ, et al. Differences in risk of malignancy and management recommendations in subcategories of thyroid nodules with atypia of undetermined significance or follicular lesion of undetermined significance: the role of ultrasound-guided coreneedle biopsy. Thyroid 2014;24:494-501 CrossRef Medline

30. Na DG, Min HS, Lee H, et al. Role of core needle biopsy in the management of atypia/follicular lesion of undetermined significance thyroid nodules: comparison with repeat fine-needle aspiration in subcategory nodules. Eur Thyroid J 2015;4:189-96 CrossRef Medline

31. Degirmenci B, Haktanir A, Albayrak R, et al. Sonographically guided fine-needle biopsy of thyroid nodules: the effects of nodule characteristics, sampling technique, and needle size on the adequacy of cytological material. Clin Radiol 2007;62:798 - 803 CrossRef Medline

32. Choi SH, Han KH, Yoon JH, et al. Factors affecting inadequate sampling of ultrasound-guided fine-needle aspiration biopsy of thyroid nodules. Clin Endocrinol (Oxf) 2011;74:776-82 CrossRef

33. Moon HJ, Kwak JY, Kim EK, et al. Ultrasonographic characteristics predictive of nondiagnostic results for fine-needle aspiration biopsies of thyroid nodules. Ultrasound Med Biol 2011;37:549-55 CrossRef Medline

34. Choi SH, Baek JH, Lee JH, et al. Thyroid nodules with initially nondiagnostic, fine-needle aspiration results: comparison of core-needle biopsy and repeated fine-needle aspiration. Eur Radiol 2014;24: 2819-26 CrossRef Medline

35. Raab SS, Vrbin CM, Grzybicki DM, et al. Errors in thyroid gland fine-needle aspiration. Am J Clin Pathol 2006;125:873-82 CrossRef Medline

36. Yeh MW, Demircan O, Ituarte P, et al. False-negative fine-needle aspiration cytology results delay treatment and adversely affect outcome in patients with thyroid carcinoma. Thyroid 2004;14: 207-15 CrossRef Medline

37. Ha EJ, Baek JH, Lee JH, et al. Sonographically suspicious thyroid nodules with initially benign cytologic results: the role of a core needle biopsy. Thyroid 2013;23:703-08 CrossRef Medline

38. Ylagan LR, Farkas T, Dehner LP. Fine needle aspiration of the thyroid: a cytohistologic correlation and study of discrepant cases. Thyroid 2004;14:35-41 CrossRef Medline

39. $\mathrm{Wu} \mathrm{HH}$, Jones JN, Osman J. Fine-needle aspiration cytology of the thyroid: ten years experience in a community teaching hospital. $\mathrm{Di}$ agn Cytopathol 2006;34:93-96 CrossRef Medline

40. Baloch ZW, Sack MJ, Yu GH, et al. Fine-needle aspiration of thyroid: an institutional experience. Thyroid 1998;8:565-69 CrossRef Medline

41. Baek JH, Lee JH, Valcavi R, et al. Thermal ablation for benign thyroid nodules: radiofrequency and laser. Korean J Radiol 2011;12: 525-40 CrossRef Medline

42. Bongiovanni M, Krane JF, Cibas ES, et al. The atypical thyroid fineneedle aspiration: past, present, and future. Cancer Cytopathol 2012; 120:73-86 CrossRef Medline

43. Harvey JN, Parker D, De P, et al. Sonographically guided core biopsy in the assessment of thyroid nodules. J Clin Ultrasound 2005;33: 57-62 CrossRef Medline 